\title{
Littérature et sida, alors et encore
}

Editors: Alessandro Badin, Stefano Genetti, Fabio Libasci, and Jean-Marie Roulin

Trois décennies après l'émergence du VIH, à l'ère du «post-sida », deux générations de chercheurs dressent le bilan des représentations qu'en a données la littérature française. Depuis les premiers pseudo-témoignages jusqu'à l'historicisation du sida, à l'intériorisation du deuil et à l'insurrection contre la sérophobie, autour de l'œuvre de Guibert et d'autres écrivains (Hocquenghem, Lagarce, Dustan), se dispose toute une constellation de récits alliant autobiographie et fiction. La pluralité d'approches (études littéraires, de genre et culturelles) interroge l'actualité d'un phénomène et de ses multiples implications, aussi bien intimes que politiques, esthétiques que morales. Le VIH/sida s'avère un opérateur herméneutique pour explorer le corps et la maladie, le désir et la mort, pour rompre le silence et repenser l'identité.

In the 'post-AIDS era', three decades after the emergence of HIV, two generations of researchers take stock of its representations in French literature. A whole constellation of narratives combining autobiography and fiction has formed around the works of Guibert and other authors (Hocquenhem, Lagarce, Dustan), from the initial pseudo-testimonials to texts historicising AIDS, internalising grief, or protesting against AIDS/HIV discrimination. Calling on a variety of approaches (literary studies, gender studies, and cultural studies), this volume...

See More

Readership

Researchers, students, and readers with an interest in writing of the self, in the relationships between autobiographical or fictional writing and illness, and, above all, in literary representations of AIDS and their socio-political, philosophical, aesthetic, and identity-related implications.

Language:

French

Subjects:

Criticism \&

Theory,

Literature and

Cultural Studies,

French \&

Francophone,

Literature and

Cultural Studies,

Cultural Studies,

Social Sciences

Publisher: Brill

Series:

C.R.I.N.: Cahiers

de recherche des

instituts

néerlandais de

langue et de

littérature

française,

Volume: 62

E-Book (PDF)

Released online: o7 Sep 2016

ISBN: 978-90-

04-32597-5

List price

USD \$104.00

Paperback 
l'intime, aux rapports entre écriture autobiographique ou fictionnelle et maladie et surtout aux représentations littéraires du sida et à leurs implications identitaires, socio-politiques, philosophiques et esthétiques.
Publication date:

29 Sep 2016

ISBN: $978-90-$

04-32279-O

List price

USD $\$ 104.00$ 
Alessandro Badin est l'auteur d'une thèse intitulée Écritures du sida, écritures de l'intime : Hervé Guibert, Cyril Collard et JeanLuc Lagarce réalisée dans le cadre d'une cotutelle entre l'Université de Vérone et l'Université Jean Monnet de SaintÉtienne. Il s'intéresse également à la littérature du Maghreb écrite en français et à la "littérature beur".

Stefano Genetti enseigne la littérature française à l'Université de Vérone. Il s'occupe principalement des XXe et XXIe siècles (Beckett, Quignard, aphorismes et fragments, rapports entre littérature et danse, études de genre). Il a consacré quelques articles aux écritures du sida.

Fabio Libasci prépare, à l'Université de Vérone en co-tutelle avec l'Université Paris 8 , une thèse de doctorat sur l'herméneutique de soi chez Hervé Guibert. Il s'intéresse aux rapports entre le discours médical et l'écriture littéraire chez Proust, à l'écriture du fragment, notamment chez Roland Barthes, et aux rapports entre vie philosophique et vie d'artiste au XXe siècle.

Jean-Marie Roulin, professeur de littérature française à l'Université de Saint-Étienne et chercheur à l'UMR LIRE, travaille sur les représentations de la société, des genres et de l'histoire des Lumières au Romantisme. Il a collaboré au numéro d'Équinoxe intitulé Le Sida et les lettres (1991).

For more information see brill.com

Order information: Order online at brill.com +44330 333 0049 | customerservices@brill.com Submission information: brill.com/authors

Titles published by Brill | Fink, Brill | mentis or Brill | Schöningh: +49(o)71 5413279216 | brill@brocom.de 